\title{
HIGH-ASPECT RATIO MICROSTRUCTURES IN BOROSILICATE GLASS BY MOLDING AND SACRIFICIAL SILICON ETCHING: CAPABILITIES AND LIMITS
}

A. Amnache $e^{1,2^{*}}$ and L.G. Fréchette ${ }^{1,2}$

${ }^{1}$ Institut Interdisciplinaire d'Innovation Technologique (3IT), Université de Sherbrooke, Sherbrooke, Québec, Canada

${ }^{2}$ Laboratoire Nanotechnologies Nanosystèmes (LN2), CNRS UMI-3463, Université de Sherbrooke, Sherbrooke, Québec, Canada

\section{ABSTRACT}

We have demonstrated a microfabrication technique to create very high aspect-ratio and vertical structures in borosilicate glass. By molding glass in deep silicon trenches, we achieved glass structure aspect-ratios of 42 , heights of $212 \mu \mathrm{m}$ and vertical wall angles up to $89.7^{\circ}$. We also parametrized the impact of molding parameters (heat treatment time and temperature) and defined the process limitations for defect free structures.

\section{INTRODUCTION}

Borosilicate glass is a material of interest in MEMS for optical devices (optical transparency), bioMEMS (chemical stability), power MEMS (thermal isolation), and packaging (electrical isolation). From a fabrication stand-point, borosilicate glass can be anodically bonded to silicon and has a similar thermal expansion coefficient. Unlike for silicon, the state-of-the-art microfabrication etching techniques for glass have limited capabilities to fabricate high aspect-ratio (AR) structures with high verticality. Alternatively, glass molding appears promising. This technique is based on a heat treatment of glass above its softening temperature, allowing it to flow under its own weight or a pressure gradient. Using a mold, we can create different geometries such as trenches, walls or membranes. For example, Kawai et al. have realized up to $50 \mu \mathrm{m}$ height glass (Pyrex 7740) microgeometries achieving aspect-ratios of 8 . They used a silicon mold which is manufactured by deep reactive ion etching (DRIE). Haque et al. also demonstrated the implementation of this technique in specific applications in particular a capacitive pressure sensor and a hermetically sealed resonator. These two studies illustrated the potential of the molding technique to fabricate vertical structures in glass. However, the effect of molding parameters were not studied i.e. the heating time and temperature. Liu et al. have characterized the effect of heat treatment time and temperature on the molding of Pyrex glass, but the study was done on large trenches (width of $1.5 \mathrm{~mm}$ and $210 \mu \mathrm{m}$ depth). Since, they used tetramethylammonium hydroxide (TMAH) wet etching to manufacture the silicon mold, the mold walls were not vertical. In fact, the heated glass bends rather than flows into trenches.

Despite the relevance of molding to create precise glass geometries [1, 2], the limits of the process for high aspect-ratios and the impact of process conditions on the molding capabilities are not well understood. Although Haque et al. have reported the challenges to ensure the full filling of the silicon trenches. Additionally, there is no quantitative study of the aspect-ratio dependent molding (ARDM), defined here as the non-uniform velocity of the glass as it flows down trenches of different widths to fill them. So, what is the maximum achievable aspect-ratio by molding borosilicate glass, and what controls this limit?

In this work, we aimed to conduct glass molding into Si DRIE high aspect-ratio trenches and characterize the glass flow behavior as a function of both the micro-trench width and heat treatment temperature to define the molding flow rate and quality. This work aims to obtain a quantitative study of the glass molding to form vertical microstructures in the borosilicate glass as well as the limits of this technique.

\section{MICROFABRICATION PROCESS}

The process flow for the fabrication of borosilicate glass microstructures is described in Fig. 1. First, deep trenches are created in a silicon wafer ( $500 \mu \mathrm{m}$ thick) by DRIE. The etching time was $70 \mathrm{~min}$ to reach up to $230 \mu \mathrm{m}$ deep. AZ9245 photoresist was used as a mask. The width of trenches is 12, 23, 54, 104, 254 and $506 \mu \mathrm{m}$ (Fig. 1a). The etched Si wafer and a Borofloat 33 glass wafer $(500 \mu \mathrm{m}$ thick) were cleaned in a Piranha solution $(1: 2$ mixture of $\mathrm{H}_{2} \mathrm{O}_{2}: \mathrm{H}_{2} \mathrm{SO}_{4}$ ) for $15 \mathrm{~min}$, and then the two wafers were anodically bonded in an AML-AWB-04-30 bonder (Fig. 1b). The bonding process is done under vacuum $\left(\mathrm{O}_{2}, 150\right.$ mTorr $)$ at a voltage of $500 \mathrm{~V}$ to form closed low pressure micro-cavities from the array of trenches. The bonding contact force was $200 \mathrm{~N}$, applied uniformly through the surface of $100 \mathrm{~mm}$ diameter wafers. Both wafers were heated simultaneously to $370{ }^{\circ} \mathrm{C}$ during bonding process. Afterwards, the bonded wafer was diced into square pieces of $15 \mathrm{~mm}$ per side. The sample is then heated in an atmospheric furnace and, the pressure difference across the softened glass will push against the viscous forces of the flowing glass (Fig. 1c). The heating temperature and time of treatment were varied. Nitrogen with $100 \mathrm{sccm}$ was used as an environment gas. Since the top glass surface will deform, lapping and polishing of the surface is done to planarize and smooth the surface (Fig.1.d). To create glass structures, the silicon mold is removed by a Potassium hydroxide (KOH) etching (Fig.1.e)
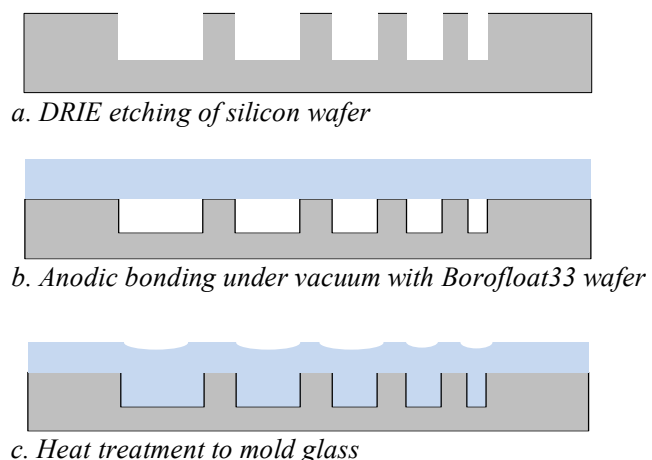

c. Heat treatment to mold glass

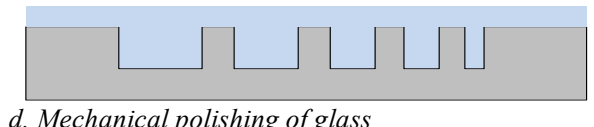

d. Mechanical polishing of glass

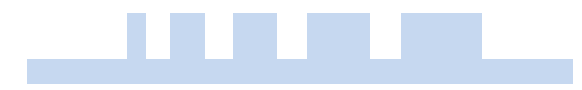

e. KOH silicon etching to create glass structures

Figure 1: Microfabrication process flow of molding glass into silicon trenches and releasing.
Solid-State Sensors, Actuators and Microsystems Workshop Hilton Head Island, South Carolina, June 5-9, 2016 


\section{EXPERIMENT AND RESULTS}

\section{Heat Treatment}

A series of 25 samples were tested by varying temperature in the range of $750-950^{\circ} \mathrm{C}$ and heating time from 10 min to 32 hours. The heating treatment is characterized by five steps. In the first step, the bonded sample is heated rapidly from ambient temperature to $400{ }^{\circ} \mathrm{C}$ by an uniform heating rate of $12.6^{\circ} \mathrm{C} / \mathrm{min}$. Afterwards, the heating is continued to up the desired treatment temperature at a rate of $3^{\circ} \mathrm{C} / \mathrm{min}$. After the isothermal heat treatment, the sample is cooled to a temperature of $400{ }^{\circ} \mathrm{C}$ with a controlled cooling rate of $0.7{ }^{\circ} \mathrm{C} / \mathrm{min}$. Finally, the cooling is continued without controlling the rate by free convection inside the oven down to room temperature for $750 \mathrm{~min}$.

\section{Molding Evolution in Silicon Trenches}

Fig. 2 shows an example of glass flow evolution in the trenches at $850^{\circ} \mathrm{C}$ and for different time steps $(1,2,4$ and $6 \mathrm{~h})$. The SEM cross-section images indicate clearly that there is ARDM for narrow trenches, i.e. the glass flows faster in the wide trenches compared to narrower ones. Since the pressure difference remains substantially constant, the ARDM is due to the viscous effects that are more significant at smaller dimensions.

The variation of the flow length versus heating time is plotted in Fig. 3 for different heating temperatures and trench widths. The error bars were determined by measuring variation of the flow length between different trenches having same dimensions and at the same heat treatment parameters. For a fixed trench width, the flow length increases linearly with the heating time. This linear trend in the data demonstrates that the flow velocity is a constant quantity for a given temperature and trench width. The flow velocity is then the slope of a fitted line. Extrapolation of this data to the heating time equal to zero gives an intercept. This intercept represents the total flow length during the period of heating (before the desired treatment temperature is reached) and cooling. The flow length in the trench widths of $506 \mu \mathrm{m}$ is not represented because they were completely filled during the heating ramp, before reaching the desired treatment temperature.

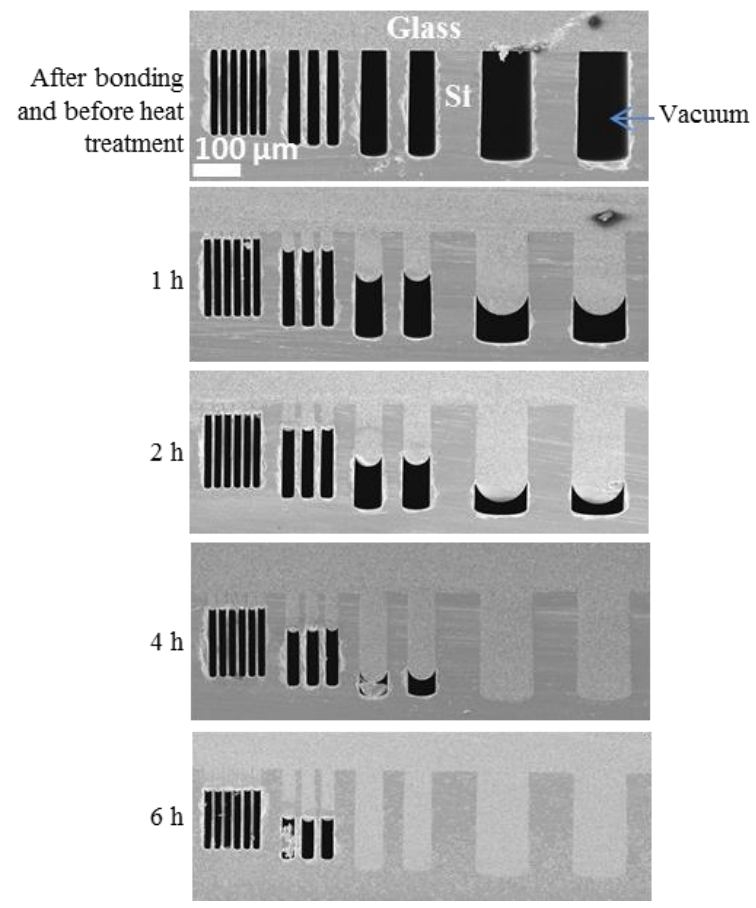

Figure 2: SEM photographs showing the time effect on the molding glass length through silicon trenches for a molding temperature of $850^{\circ} \mathrm{C}$.

\section{Glass Flow Velocity}

Using the slopes of the plots in Fig. 3, values of glass flow velocity were calculated. Fig. 4 shows the relationship between glass flow velocity and heat treatment temperature for three different trench widths, 12,23 and $54 \mu \mathrm{m}$. The plots indicate that velocity increases with the heat treatment temperature, following a quadratic trend.

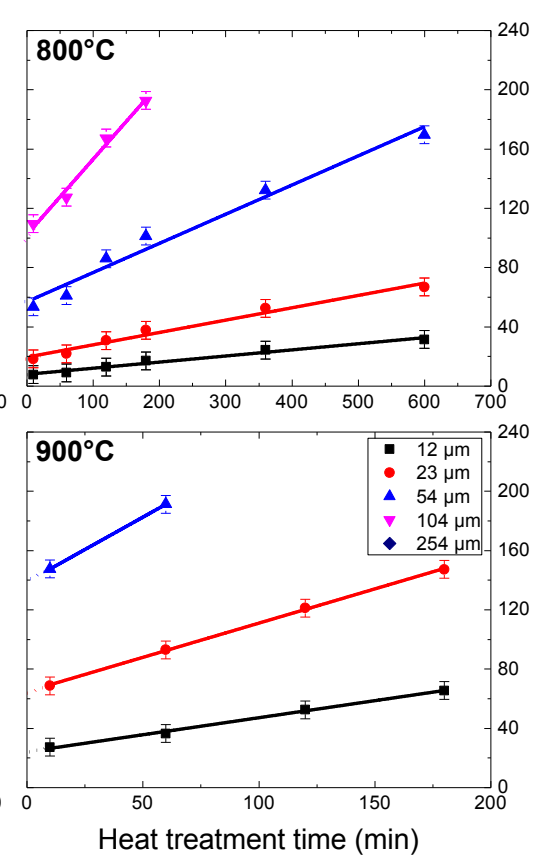

Figure 3: Measured flow length as a function of molding temperature and trench width. 


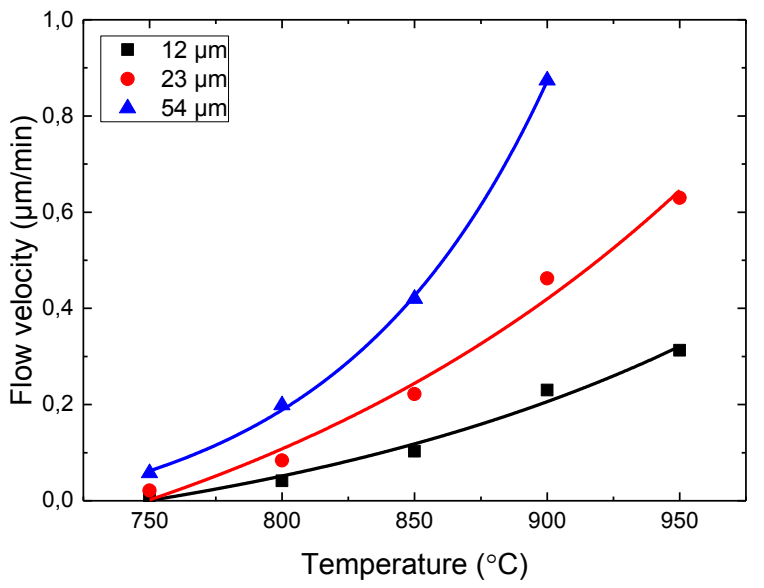

Figure 4: Extracted flow velocity as a function of molding temperature and trench width. The velocity is calculated by linear fitting the data in Fig. 3

This is due to the glass viscosity decreasing as the temperature increases. Additionally, the plots show that the flow velocity is higher in wider trenches. This observation is attributed to the shear friction forces between the flowing glass and trench walls.

\section{Limits of Borosilicate Glass Molding}

As the heat treatment time is increased at a given temperature, two effects are observed in the molded glass. The first one is defects on the glass surface. The defects become deeper as the heat treatment time increases. The second one is the appearance of voids at the glass/Si interface when the heat treatment time is much longer. Fig. 5 shows the conditions of heat treatment when these two effects appear. We have identified three zones for the molding of borosilicate glass. In the first zone the molding gave high quality results as shown in Fig. 5a. In the second zone, the molding shows defects on the surface as seen in Fig. 5b. However, these defects in the glass can be removed by a simple mechanical polishing.

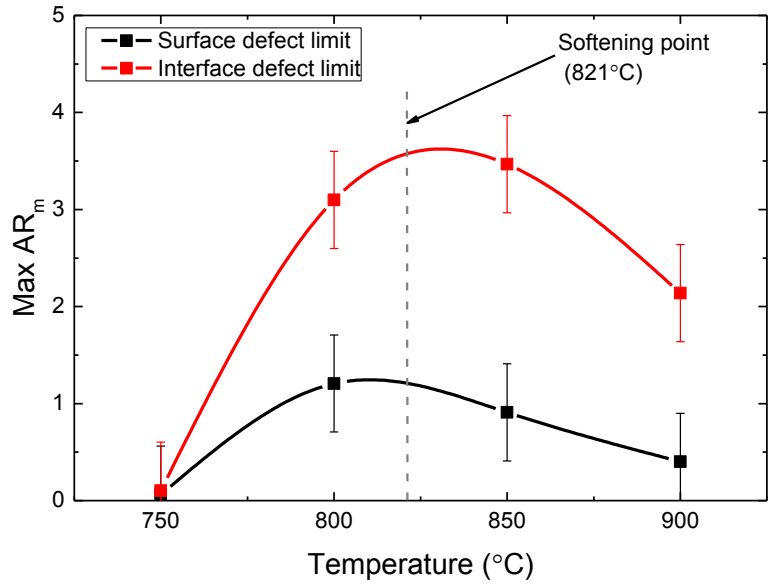

Figure 6: Maximum achievable aspect-ratio by molding borosilicate glass into silicon trenches before the appearance of defects. The width of trenches is $23 \mu \mathrm{m}$.

Finally, in the third zone, the molded glass showed defects on the surface and voids at the Si/glass interface as seen in Fig. 5c and Fig. $5 \mathrm{~d}$. These limitations of the heat treatment time suggest that there is a maximum aspect-ratio as molded, $\mathrm{AR}_{\mathrm{m}}$, that can be obtained by molding borosilicate glass. Note that the $\mathrm{AR}_{\mathrm{m}}$ is different than the aspect-ratio of the released microstructures. $A_{\mathrm{m}}$ is defined as the ratio of the glass flow length and the width of trenches. On the other hand, the AR characterizes, in the present work, the final glass geometries after removing the silicon mold. The $\mathrm{AR}$ can be greater than the $\mathrm{AR}_{\mathrm{m}}$. By combining the results concerning the flow velocity (Fig. 4) and the heat treatment time limit (Fig. 5) we have calculated the maximum $\mathrm{AR}_{\mathrm{m}}$ that can be achieved. Fig. 6 shows the influence of the heat treatment temperature on the maximum $\mathrm{AR}_{\mathrm{m}}$ for two limits that are surface and interface limit. The plots indicate that the $\mathrm{AR}_{\mathrm{m}}$ has a largest value at around the softening point of the Borofloat 33 glass i.e. $821^{\circ} \mathrm{C}$. This is therefore the optimal temperature giving the best results for molding borosilicate glass.

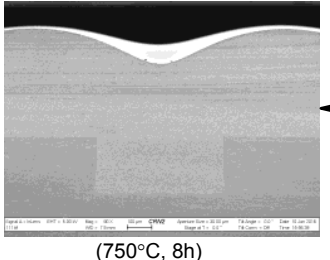

(a)

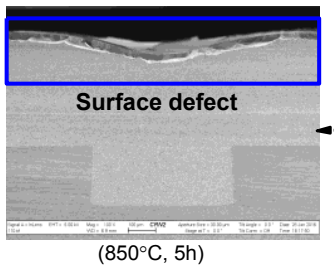

(b)

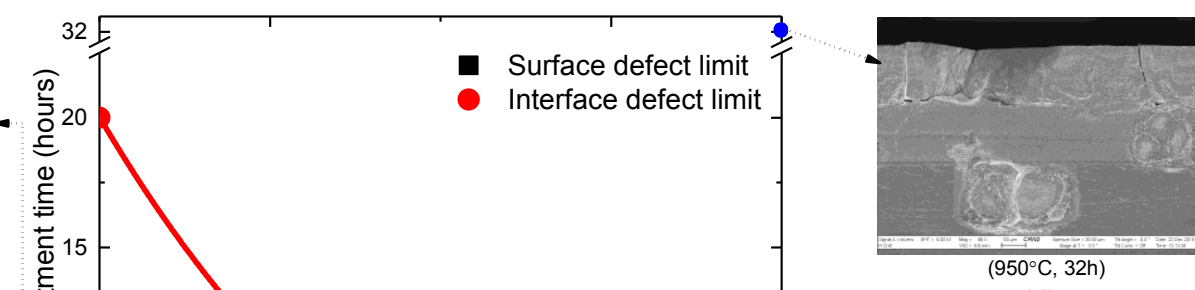

(d)

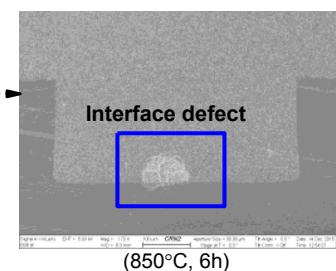

(c)

Figure 5: Temperature and heating time limits of molding borosilicate glass in silicon trenches. The chart is characterized by three zones. Zone 1: the molding gives high quality results. Zone 2: void formation on the glass surface. Zone 3: void formation on the Si/glass interface and on the surface of glass substrate. 


\section{Fabrication of High Aspect-ratio Structures}

In order to create glass structures, the molded samples were immersed in $\mathrm{KOH}$ solution $(45 \%)$ heated at a temperature of $95^{\circ} \mathrm{C}$ to fully remove the $\mathrm{Si}$ mold. The etch rate of the $\mathrm{Si}$ and the molded borosilicate glass was $2 \mu \mathrm{m} / \mathrm{min}$ and $50 \mathrm{~nm} / \mathrm{min}$ respectively, for a selectivity of $40: 1$. Structures with a verticality of up $89.7^{\circ}$, depth of $212 \mu \mathrm{m}$ and aspect-ratio of 3 were fabricated as showed in Fig. 7a. The glass was molded in $100 \mu \mathrm{m}$ width and $220 \mu \mathrm{m}$ depth trenches at $850^{\circ} \mathrm{C}$ for $180 \mathrm{~min}$. The necessary $\mathrm{KOH}$ etching time to remove the silicon mold was $250 \mathrm{~min}$. High aspect-ratios can be achieved by over-etching the glass structures after removing the silicon mold as shown in Fig. 7b. In this case, the glass was molded in $50 \mu \mathrm{m}$ width and $220 \mu \mathrm{m}$ depth trenches at $850^{\circ} \mathrm{C}$ for $330 \mathrm{~min}$. The $\mathrm{KOH}$ over-etching has narrowed the structures to a width of $8 \mu \mathrm{m}$ and $1.9 \mu \mathrm{m}$ at the bottom and the top of the structures respectively. The over-etching time was $400 \mathrm{~min}$. An aspect-ratio of up 42 was achieved; based on the average width.
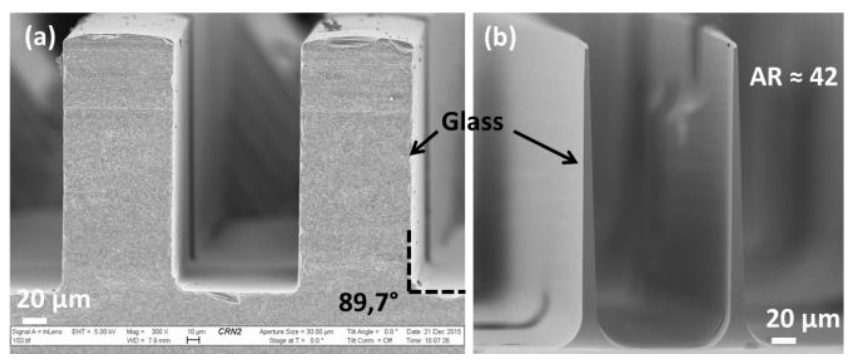

Figure 7: SEM of borosilicate glass structures fabricated by molding glass into silicon deep trenches, after, silicon has been removed by $K O H$ etching. (a) $A R \approx 3$, height $=212 \mu \mathrm{m}$, wall angle $=89.7^{\circ}$. (b) $A R \approx 42$, height $=207 \mu \mathrm{m}$, wall angle $=88.6^{\circ}$.

Fig. 8 shows a range of best results of wall angles of borosilicate glass structures obtained using plasma etching and glass molding. Compared to these studies, the molding technique performed in the present work has shown distinguished results in term of wall verticality and structures depth. The wall angle of $89.7^{\circ}$ obtained in this work is one of the best results when compared to other studies such as $88^{\circ}$ with $120 \mu \mathrm{m}$ depth obtained by Queste $e t$ al., $89^{\circ}$ with $15 \mu \mathrm{m}$ depth by Ichiki et al. and $87^{\circ}$ with $100 \mu \mathrm{m}$ depth obtained by Ahamed et al.

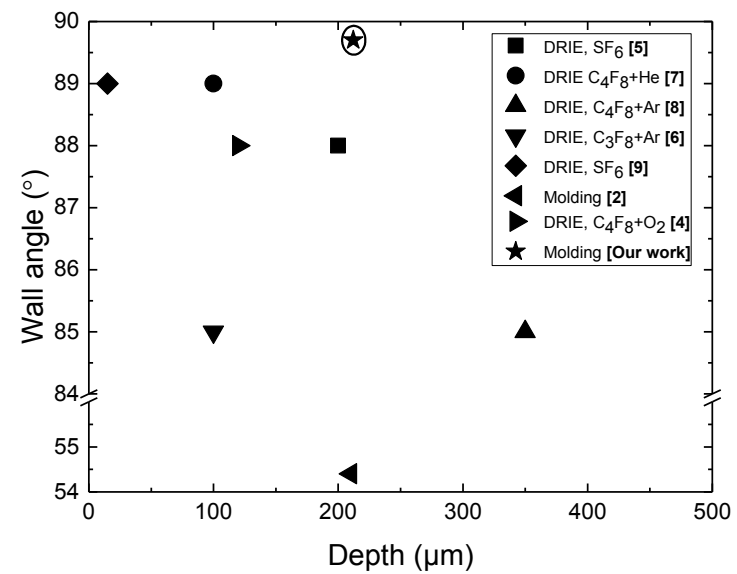

Figure 8: Comparison of wall angle results from this work and from the literature.

\section{CONCLUSION}

This work demonstrates that high aspect-ratios and high wall verticality are achievable in borosilicate glass by molding. With the obtained results, we are able to control precisely the fabrication of glass microstructures. Even though this method showed notable capabilities, it presented limits in term of heating time and temperature.

\section{ACKNOWLEDGEMENTS}

The authors gratefully acknowledge the support of the Natural Sciences and Engineering Research Council of Canada (NSERC). The fabrication work was performed at the Laboratoire Nanotechnologies Nanosystèmes (LNN).

The authors are grateful to the Transducer Research Foundation for their travel support.

\section{REFERENCES}

[1] F. Kawai, F.Y. Yamaguchi, A. Nakahara, and S. Shoji, "Fabrication of vertical and high-aspect-ratio glass microfluidic device by borosilicate glass molding to silicon structures", 14th International Conference on miniaturized systems for chemistry and life sciences, Groningen, The Netherlands, 10/3-7/10, MicroTAS, (2010), pp. $1193-1195$.

[2] J. Liu, J. Shang, J. Tang, and Q. Huang, "Micromachining of Pyrex 7740 glass by silicon and vacuum anodic bonding", Journal of Microelectromechanical Systems, 20, 4 (2011).

[3] R.M. Haque and K.D. Wise, "A glass-in-silicon reflow process for three-dimensional microsystems", Journal of Microelectromechanical Systems, 22, 6 (2013).

[4] S. Queste, R. Salut, S. Clatot, J.-Y. Rauch and C.G.K Malek, "Manufacture of microfluidic glass chips by deep plasma etching, femtosecond laser ablation, and anodic bonding", Microsystem Technologies, 16, 8 (2010).

[5] X. Li, T. Abe, Y. Liu and M. Esashi, "Fabrication of highdensity electrical feed-throughs by deep-reactive-ion etching of Pyrex glass", Journal of Microelectromechanical Systems, 11, 6 (2002).

[6] M.J. Ahamed, D. Senkal, A.A. Trusov and A.M. Shkel, "Study of high aspect ratio NLD plasma etching and postprocessing of fused silica and borosilicate glass", Journal of Microelectromechanical Systems, 24, 4 (2015).

[7] K. Kolari, V. Saarela and S. Franssila, "Deep plasma etching of glass for fluidic devices with different mask materials", Journal of Micromechanics and microengineering, 18, 6 (2008).

[8] T. Akashi and Y. Yoshimura, "Profile control of a borosilicate-glass groove formed by deep reactive ion etching", Journal of Micromechanics and microengineering, 18,10 (2008).

[9] T. Ichiki, Y. Sugiyama, R. Taura, T. Koidesawa and Y. Horiike, "Plasma applications for biochip technology", Thin Solid Films, 435, 1-2 (2003).

\section{CONTACT}

*A. Amnache, tel: +1-819-919-3254;

amrid.amnache@usherbrooke.ca 